Research Article

\title{
Novel Synthetic-Based Drilling Fluid through Enzymatic Interesterification of Canola Oil
}

\author{
Anawe A. L. Paul $(\mathbb{D})$ and Folayan J. Adewale $(\mathbb{D}$ \\ Department of Petroleum Engineering, College of Chemical and Petroleum Engineering, Covenant University, Ota, Nigeria \\ Correspondence should be addressed to Anawe A. L. Paul; paul.anawe@covenantuniversity.edu.ng
}

Received 24 March 2018; Revised 28 May 2018; Accepted 4 June 2018; Published 1 August 2018

Academic Editor: Michael Harris

Copyright (c) 2018 Anawe A. L. Paul and Folayan J. Adewale. This is an open access article distributed under the Creative Commons Attribution License, which permits unrestricted use, distribution, and reproduction in any medium, provided the original work is properly cited.

\begin{abstract}
Over the years, the oil industries have avoided aromatic, naphthenic, and paraffinic oils as drilling mud base fluids principally because of their detrimental environmental issues on pelagic and benthic marine ecosystems as a result of their toxicity and nonbiodegradability coupled with the possible deterioration of the oil itself and the rubber parts of the drilling equipment because the aromatic hydrocarbons present in the oil have a tendency to dissolve/damage elastomers present in rubber. Hence, possible insights into how to chemically and/or physically produce synthetic base drilling fluids whose cuttings are nontoxic, readily biodegradable, environmentally friendly, and of nonpetroleum source become imperative. In this study, enzymatic interesterification of canola oil was done with ethanol by using enzyme lipase as catalyst under optimum conditions of temperature and pressure and the physicochemical properties of the produced ester were evaluated and compared with that of diesel and a synthetic hydrocarbon base fluid (SHBF). Results show that the specific gravity, kinematic viscosity, dynamic viscosity, and surface tension of canola oil were reduced by $5.50 \%, 94.74 \%, 95.03 \%$, and $9.38 \%$, respectively, upon enzymatic interesterification to conform to standard requirements. Similarly, increased |mud ability to pump fluids and possibility of cold temperature environment can be achieved with the reduction in pour point and cloud point, respectively, of the produced canola oil ester. Finally, the produced ester showed no aromatic content as confirmed from its FTIR analysis which indicates its nontoxicity, biodegradability, and environmental friendliness.
\end{abstract}

\section{Introduction}

Drilling fluids are complex fluid mixtures which are principally formulated to carry cuttings from beneath the bit, transport them up the annulus and permit their separation at the surface, and prevent the inflow of formation fluids (oil, gas, and water) from the permeable rock that is being penetrated and to form a thin, low-permeability filter cake which seals pores and other openings in formations penetrated by the bit.

The oil industry started with water base fluids but because of formation clays that react, swell, or slough after exposure to water-based mud coupled with the need to penetrate a hole with high temperature, a shift to dieselbased mud began in 1960s [1]. In order to mitigate the environmental and technical issues associated with dieselbased mud, which include high initial cost per barrel, difficulties in detection of gas kick, high cost of lost circulation, difficulties in keeping the rig clean, and easy deterioration of the rubber part of the drilling equipment; hence, an alternative drilling fluid from nonpetroleum origin becomes imperative.

Diesel is also harmful to the environment particularly marine environment during offshore drilling [2]. OBFs, particularly those made with diesel are more persistent in sediments. Grahl-Nielsen et al. [3] reported little change over five years in the area of sea bottom near a single exploratory well in the North Sea that contained 1,000 to $10,000 \mathrm{mg} / \mathrm{kg}$ OBF from the discharge of OBF cuttings.

In many countries that are developing offshore oil and gas resources, cuttings discharge permits require performance of toxicity tests with drilling fluid ingredients and whole drilling fluids [4]. One of the objectives in developing environmentally acceptable alternatives to OBFs was to produce a drilling fluid that would provide the drilling 
performance of an OBF but would degrade rapidly following discharge to the ocean.

The most important fluid properties that may affect environmental impacts are toxicity and rate of biodegradation. Environmental impacts that may result from the discharge of drilling fluids and cuttings to the ocean are of two types: effects on water column (pelagic ecosystems) and effects on sea bottom (benthic ecosystems) [5-7].

The Norwegian regulatory authority defines a SBF as a drilling fluid where the base fluid consists of nonwater soluble organic compounds and where neither the base fluid nor the additives are of petroleum origin [8]. These synthetic base fluids may be classified into four general categories, namely, synthetic hydrocarbons, ethers, esters, and acetals.

However, polymerized olefins such as linear alpha olefins (LAOs), poly alpha olefins (PAOs), and internal olefins (IOs) are the most frequently used synthetic hydrocarbons, and they have been reclassified as environmentally unacceptable and are no longer in use because they contain a benzene molecule which is aromatic and nonbiodegradable [9].

Synthetic-based muds (SBMs) were developed to replace OBMs in difficult drilling situation, and though SBMs are expensive than OBMs, they have superior environmental properties that may permit the cuttings to be discharged on-site [10].

Veil et al. [11] describe the environmental benefits of synthetic-based drilling muds to include less waste production from a recyclable product (compared to WBMs); elimination of diesel as a mud base lessens the pollution hazard, improves worker safety through lower toxicity, diminishes irritant properties, and reduces consequent risk (compared to OBMs); increased use of horizontal drilling reduces the areal extent and the environmental impacts of offshore oil and gas operations (compared to WBMs); shortened drilling time results in reduced air emissions from drilling power sources; and improved drilling performance decreases waste-generating incidents, such as pipe stuck in the hole. Mineral oils are less biodegradable than SBF chemicals particularly under anaerobic conditions.

All the SBF base chemicals evaluated by Norman [12] and Steber et al. [13] have measurable aerobic and anaerobic biodegradability. Aerobic and anaerobic biodegradation rates are greatest for ester SBFs, followed by IOs. Meanwhile, Candler et al. [14] ranked both aerobic and anaerobic biodegradability of drilling fluid base chemicals from most to least biodegradable as

$$
\text { esters } \gg \text { LAOs }>\text { IOs } \gg \text { PAOs }>\text { mineral oil. }
$$

Environmental authorities of the North Sea countries have hypothesized that rapid degradation will minimize the environmental impacts of SBF cuttings discharge and thus speeding ecosystem recovery [15].

\section{Materials and Methods}

2.1. Canola Oil. Canola oil (Canada oil) is processed from the seed of Brassica napus and Brassica rapa which can be extracted by either solvent extraction method or expeller method. Edible oils and fats composed primarily of triglycerides which are ester of one molecule of glycerol and three molecule of fatty acid. Canola oil analyses show that the triglycerides constitute 94.4 to $99.1 \%$ of the total lipid and about $2.5 \%$ phospholipids [16]. It has been established that the 18 carbon fatty acids account for about $95 \%$ of canola's total fatty acid [17]. It has a larger percentage of oleic acid (about $56 \%$ ) followed by linoleic acid (26\%), linolenic acid (10\%), and $4 \%$ palmitic acid with only $2 \%$ stearic acid [18].

2.2. Interesterification Reaction. From the three main oil modification technologies (fractionation, hydrogenation, and interesterification), interesterification is by far the easiest process to understand and to control [19]. Interesterification process is used to modify the physical properties of the oil or fat blend by rearranging the fatty acid groups within and between the different triglycerides.

Interesterification is the process of exchanging the organic group $\mathrm{R}^{\prime \prime}$ of an ester with the organic group $\mathrm{R}^{\prime}$ of an alcohol. These reactions are often catalyzed by the addition of an acid or base catalyst. The reaction can also be accomplished with the help of enzymes (biocatalysts) particularly lipases:

$\mathrm{R}^{\prime} \mathrm{OH}+\mathrm{R}_{\mathrm{R}}^{\prime \prime} \mathrm{R}_{\mathrm{R}} \longrightarrow \mathrm{OH}_{\mathrm{R}^{\prime} \mathrm{O}}$

interesterification: alcohol + ester

$\longrightarrow$ different alcohols + different esters.

Strong acids catalyze the reaction by donating a proton to the carbonyl group, thus making it a more potent electrophile, whereas bases catalyze the reaction by removing a proton from the alcohol, thus making it more nucleophilic. Esters with larger alkoxy groups can be made from methyl or ethyl esters in high purity by heating the mixture of ester, acid/base, and large alcohol and evaporating the small alcohol to drive equilibrium.

2.3. Enzymatic Interesterification Procedure. Six hundred milliliters of chemically degummed canola oil were measured and poured into a $1000 \mathrm{ml}$ PYREX Erlenmeyer flask with rubber stopper. The degummed oil was then heated to a temperature of $60^{\circ} \mathrm{C}$ in an electric oven. This was followed by the addition of $120 \mathrm{ml}$ of ethanol which was preheated to a temperature of $60^{\circ} \mathrm{C}$ with the aid of water bath. A $4 \%$ concentration of immobilized Candida antarctica lipase was then added to the oil-alcohol mixture in the flask, and the flask was then placed in an orbital shaker at $70^{\circ} \mathrm{C}$ and rotating speed of $300 \mathrm{rpm}$ for 12 hours. After the completion of the reaction time, the reaction mixture was then filtered by vacuum filtration in order to retain the enzyme for subsequent recovery and use.

The resulting filtrate was then taken to a rotary evaporator at $90^{\circ} \mathrm{C}$ (a temperature higher than the boiling point of ethanol $\left.\left(78.37^{\circ} \mathrm{C}\right)\right)$ in order to evaporate unreacted alcohol. Finally, the reaction mixture was placed in a separating funnel resulting in two distinct layers of upper ethyl ester and a lower layer of monoglyceride, diglyceride, glycerol, and other impurities. The produced ethyl ester was then bleached with $1.5 \%$ bleaching clay and deodorized, and its volume was measured in order to deduce its percentage yield: 

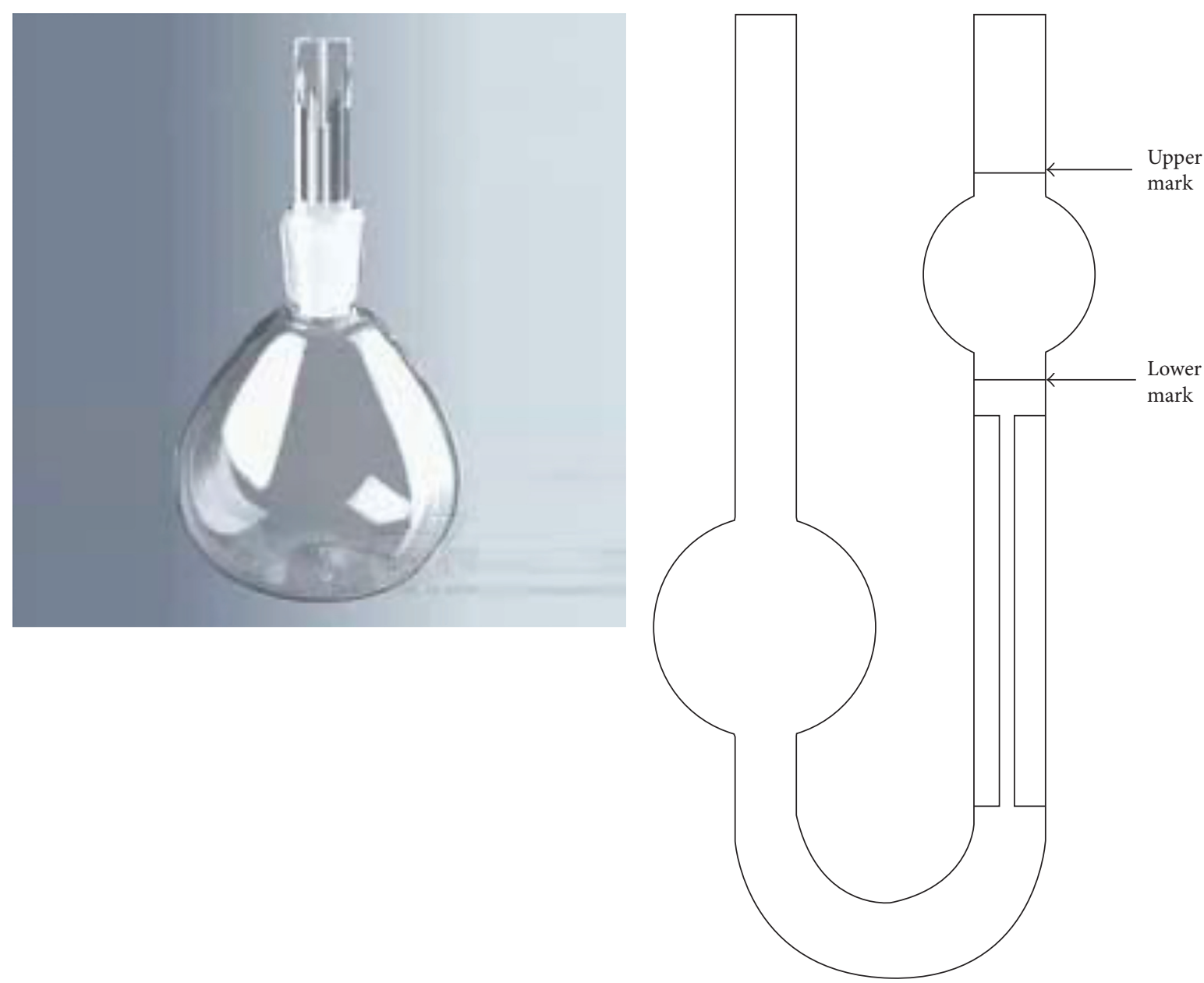

(a)

(b)
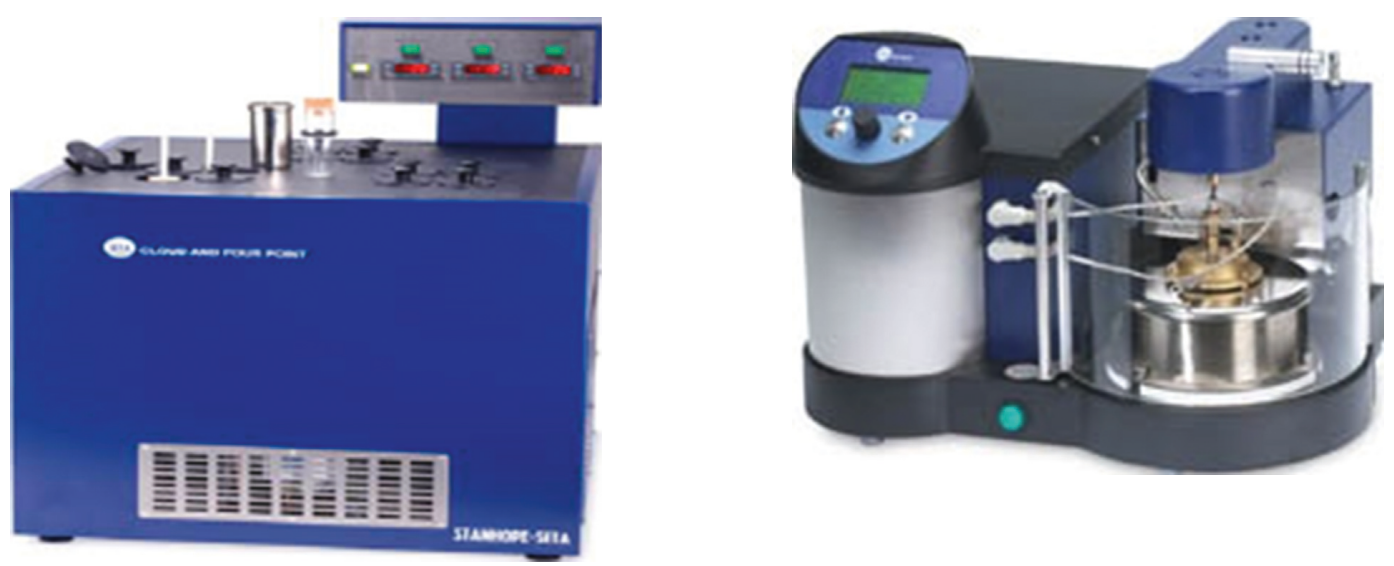

(c)

(d)

Figure 1: Continued. 


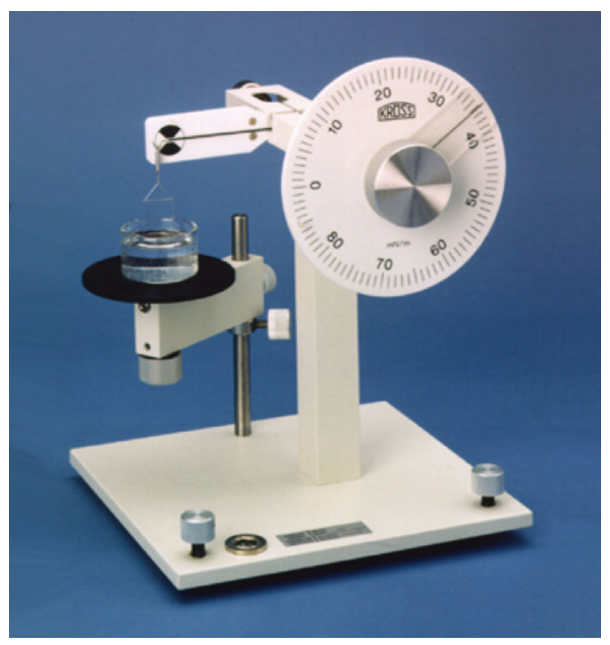

(e)

Figure 1: (a) A $50 \mathrm{ml}$ density bottle. (b) Ostwald viscometer. (c) Seta cloud and pour point cryostat [20]. (d) Seta flash point tester [21]. (e) Tensiometer.

$$
\begin{aligned}
& \% \text { yield of ester }=\left[\frac{\text { volume of ester produced }}{\text { volume of canola oil used }}\right] * 100, \\
& \% \text { yield of ester }=\left[\frac{465}{600}\right] * 100, \\
& \% \text { yield of ester }=77.50 \% .
\end{aligned}
$$

2.4. Base Fluid Property Evaluation. After the synthesis of the ethyl esters, it is imperative to determine the physicochemical properties of the esters formed and those of the control sample fluids before any mud formulation can occur in order to compare with specified standards to know if there is marked deviation such as physicochemical properties including but not limited to fluid density, kinematic viscosity, dynamic viscosity, cloud point, pour point, flash point, fire point, and surface tension.

\subsubsection{Specific Gravity Evaluation at Different Temperatures.} Experimental procedure is as follows:

(1) The density bottle was firstly dried to allow for accurate measurement of its mass as shown in Figure 1(a).

(2) The cleaned and dried density bottle was weighed using a digital weighing balance to the nearest $0.01 \mathrm{~g}$, and the weight was recorded.

(3) The density bottle was then filled completely with the fluid sample, and the stopper was inserted into the neck of the bottle resulting in spillage of the fluid outside the density bottle. This is necessary in order to avoid air being entrapped in the density bottle.

(4) The outside of the bottle was carefully dried using a soft tissue paper. The bottle and its content were weighed and the mass recorded.
(5) The liquid sample was poured out of the density bottle and the bottle was rinsed several times with distilled water and dried for subsequent samples weight determination.

(6) Water bath was then used to heat the fluid samples to the required temperatures prior to their weight measurement.

Deductions and calculations are as follows:

$$
\begin{aligned}
V_{\mathrm{db}} & =\text { volume of density bottle } \\
& =\text { volume of distilled water }=50 \mathrm{~cm}^{3}, \\
W_{\mathrm{db}} & =\text { weight of density bottle }(\mathrm{g}), \\
W_{\mathrm{fs}} & =\text { weight of fluid sample }(\mathrm{g}), \\
W_{\mathrm{db}+\mathrm{fs}} & =\text { weight of density bottle }+ \text { fluid sample }(\mathrm{g}), \\
W_{\mathrm{fs}} & =W_{\mathrm{db}+\mathrm{fs}}-W_{\mathrm{db}},
\end{aligned}
$$

hence, density $\left[\frac{\mathrm{g}}{\mathrm{cm}^{3}}\right]=\frac{W_{\mathrm{fs}}}{V_{\mathrm{db}}}$,

$$
\text { specific gravity }=\frac{\text { density of liquid }}{\text { density of equal volume of water }} \text {. }
$$

\subsubsection{Base Fluid Viscosity Determination}

(1) Method of Determining the Kinematic Viscosity of Base Fluid. The following steps were used to determine the viscosity of the fluid sample:

(1) The viscometer (Figure 1(b)) was rinsed with ethanol and dried to avoid contaminants. 
(2) The lower bulb of the viscometer was filled with the fluid sample to half of its capacity.

(3) Cold air was then blown into the viscometer so as to allow the fluid sample to travel up the viscometer at the other side of the upper mark of the bulb.

(4) The stop watch was switched on at the upper mark oil level, and it was stopped when the oil gets to the lower mark below the upper bulb. The two marks indicate a known volume and the time taken for the level of oil to pass between these marks is proportional to the kinematic viscosity.

(5) The time taken for the oil to travel to the lower bulb mark was recorded in seconds and it was converted to kinematic viscosity (in centistokes) using the viscometer size 200 constant of $0.1 \mathrm{cst} / \mathrm{sec}$.

(6) The above steps were repeated for various oil samples at different temperatures.

Mathematically, the kinematic viscosity is obtained by using the following equation:

$$
\mu=\alpha t
$$

where $\mu=$ kinematic viscosity (centistokes), $t=$ effluent time (seconds), and $\alpha=$ viscometer constant (cst/sec).

The dynamic viscosity $(v)$ can be obtained by multiplying the kinematic viscosity $(\mu)$ with the density of the fluid $(\rho)$ :

$$
v=\mu \rho \text {. }
$$

2.4.3. Cloud and Pour Points of Base Fluid Samples. The cloud point and pour point were measured by using the seta cloud and pour point cryostat shown in Figure 1(c).

The following procedures were used in the course of the experiment:

(1) One of the three (3) compartments was filled with two liters of butyl glycol.

(2) The glass cups in each of the compartments were filled with different oil samples up to the upper mark.

(3) The glass cups were covered with the thermometer cork, and the thermometer was inserted into the oil sample in the glass cup through the cork.

(4) The outer black insulating gasket and disc were placed on the glassware, and this was placed in the cryostat compartment and the power corresponding to the compartment was switched on.

(5) The glass cups were brought out on periodic intervals to check the cloudiness of the oil samples. The temperature at which the oil sample becomes cloudy is its cloud point.

(6) After recording the cloud point, the thermometer was removed, and the glass cup was inserted into the compartment and the oil samples were allowed to freeze completely.

(7) The thermometer cork was removed, and the glass cup was placed tilted on a flat table with a thermometer in it. The temperature at which the first drop of oil is formed is the pour point of the oil samples.

2.4.4. Flash Point and Fire Point of Base Fluid Samples. Flash point of a flammable liquid is defined as the lowest temperature at which it can form an ignitable mixture in air while fire point is the temperature at which vapors of the flammable liquid continue to burn after being ignited even after the source of ignition is removed.

The following procedure was used to determine the flash point of each base fluid sample by using the equipment shown in Figure 1(d):

(1) The gas supply was switched on from the gas canister filled with butane gas.

(2) The control valve on the gas canister was adjusted until the pilot jet flame is approximately $12 \mathrm{~mm}$ long.

(3) The test jet flame was also adjusted to $4 \mathrm{~mm}$ diameter by rotating the pinch valve, and the gas supply was then switched off.

(4) The flash point tester power was then switched on, and the test temperature was set by using the set temperature button.

(5) The tester sample cup was allowed to stabilize at the set temperature, and the syringe was loaded with the base fluid sample and injected into the sample cup through the filler orifice and the syringe was removed.

(6) The gas supply was then switched on, and a fire lighter was used to light and set the pilot and test jet flame at $4 \mathrm{~mm}$.

(7) At the set test temperature, a warning beep sounds.

(8) The shutter was then opened and closed over a period of five seconds.

(9) A flash was detected at the flash point of the sample, and the temperature at which the flash occurred was recoded as the flash point of the fluid sample.

(10) After the flash point, the heating was continued, and the fire point was taken as the temperature at which the application of test flame causes the oil sample to burn for at least five seconds.

(11) The sample cup was allowed to cool to room temperature.

(12) The above steps were repeated for other samples.

2.4.5. Surface Tension Determination. The surface tension of a liquid can be experimentally measured by several methods such as the drop weight method (stallagmometer), Du Nouy ring method, Wilhelmy plate method, and the maximum bubble pressure method. However, the Du Nouy ring method is a rapid, simple, and most widely used method because it does not need to be calibrated using solutions of known surface tension [22].

$\mathrm{Du}$ Nouy ring method procedure for surface tension estimation is as follows: 
(1) The measurement is performed by an instrument known as tensiometer as shown in Figure 1(e). However, the instrument does not measure surface tension directly but it has an accurate microbalance and a mechanism to vertically move the liquid sample in a glass beaker.

(2) The weight of the circular ring to be immersed into the fluid sample was measured by weighing balance and recorded as $W_{\mathrm{r}}$.

(3) The ring hanging from the hook of the balance was immersed into the fluid sample and then carefully pulled up by lowering the sample vessel.

(4) The force applied on the ring when it pulls through the air-liquid interface was continuously recorded by the microbalance.

(5) The above procedure was repeated for other fluid samples at designated temperature of $25^{\circ} \mathrm{C}$.

Hence, the total force required to detach the ring is recorded as $W_{\text {total }}$.

Mathematically,

$$
W_{\text {total }}=W_{\mathrm{r}}+4 \pi R_{\mathrm{r}} \gamma,
$$

where $W_{\text {total }}=$ the total force needed to detach the ring (Newton); $W_{\mathrm{r}}=$ weight of the circular ring immersed into the fluid sample (Newton); $R_{\mathrm{r}}=$ radius of the ring (meter); and $\gamma=$ surface tension $(\mathrm{N} / \mathrm{m})$.

From (4), the surface tension can be expressed as

$$
\gamma=\frac{W_{\text {total }}-W_{\mathrm{r}}}{4 \pi R_{\mathrm{r}}} .
$$

Equation (5) provides us with a surface tension estimation that is characterized with about $25 \%$ error. Hence, a more accurate estimation is established by introducing a surface tension correction factor $f$ as shown in (6):

$$
\gamma=\left[\frac{W_{\text {total }}-W_{\mathrm{r}}}{4 \pi R_{\mathrm{r}}}\right] f,
$$

where $f$ is the surface tension correction factor which was obtained graphically from [23] as variation of $f$ with $R_{\mathrm{r}}^{3} / V$ and $R_{\mathrm{r}} / r_{\mathrm{w}}$, in which $R_{\mathrm{r}}$ = radius of the ring (meter); $V=$ volume of the liquid raised by the ring during detachment; and $r_{\mathrm{w}}=$ radius of the ring wire.

\section{Results and Discussion}

\subsection{Base Fluid Properties Characterization}

3.1.1. Base Fluid Specific Gravity. The results of the specific gravity of the base fluids are presented in Table 1 and Figure 2. The specific gravity values are deduced from the weight of the sample shown in Table 2 . From the results, it can be inferred that the EICO base fluid has a lower specific gravity of 0.860 compared with the raw canola oil with the highest specific gravity of 0.910 at ambient temperature. The implication of specific gravity is felt in the amount of weighting material required in mud formulation to achieve the required mud weight standard. In comparison with the
TABLE 1: Base fluids' specific gravity at different temperatures.

\begin{tabular}{lcccc}
\hline Temp $\left({ }^{\circ} \mathrm{C}\right)$ & Canola oil & EICO & Diesel & SHBF \\
\hline 25 & 0.910 & 0.860 & 0.850 & 0.837 \\
50 & 0.896 & 0.842 & 0.835 & 0.818 \\
75 & 0.875 & 0.821 & 0.812 & 0.797 \\
100 & 0.862 & 0.805 & 0.785 & 0.769 \\
\hline
\end{tabular}

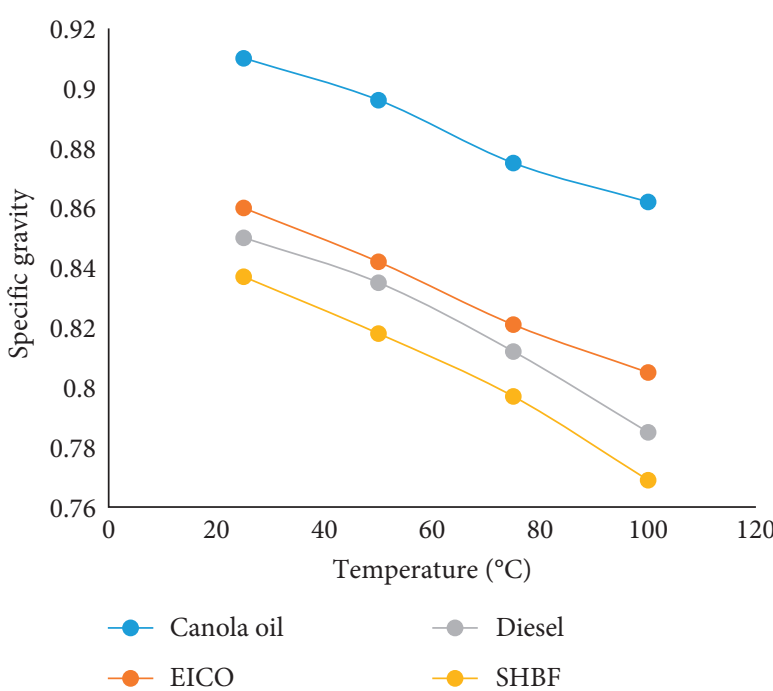

Figure 2: Specific gravity variation with temperature.

TABLe 2: Base fluids' weight in grams per $50 \mathrm{ml}$ density bottle at different temperatures.

\begin{tabular}{lcccc}
\hline Temp $\left({ }^{\circ} \mathrm{C}\right)$ & Canola oil & EICO & Diesel & SHBF \\
\hline 25 & 45.50 & 43.00 & 42.50 & 41.85 \\
50 & 44.80 & 42.10 & 41.75 & 40.90 \\
75 & 43.75 & 41.05 & 40.60 & 39.85 \\
100 & 43.10 & 40.25 & 39.25 & 38.45 \\
\hline
\end{tabular}

API standard requirement of $0.76-0.88$ for oil-based mud, it can be deduced that the EICO compares favorably with the diesel and synthetic hydrocarbon base fluid (SHBF) standards. Similarly, Hyne [24] proposed that oils with specific gravity of 25-50 API are usually the best for drilling fluid base oil. Hence, the EICO shows a promising result for base oils with specific gravity of 33 API compared with canola oil of 23 API at ambient temperature.

3.1.2. Base Fluid Viscosity. The viscosity of a fluid is a measure of its resistance to gradual deformation by shear stress or tensile stress. During the course of evaluation, two types of viscosities were used to characterize the base fluids which are dynamic (shear) viscosity and kinematic viscosity. The dynamic viscosity expresses its resistance to shearing flows, where adjacent layers move parallel to each other with different speeds while kinematic viscosity describes the resistance of a fluid to flow under gravity.

From the effluent time presented in Table 3, it can be seen that it took the canola oil more time to travel down the viscometer which translates to higher kinematic viscosities, 
TABle 3: Ostwald viscometer (size 200) effluent time (seconds) of base fluid samples.

\begin{tabular}{lcccc}
\hline Temp $\left({ }^{\circ} \mathrm{C}\right)$ & Canola oil & EICO & Diesel & SHBF \\
\hline 25 & 665 & 35 & 32 & 29 \\
50 & 254 & 27 & 24 & 21 \\
75 & 132 & 21 & 17 & 13 \\
100 & 78 & 14 & 11 & 8 \\
\hline
\end{tabular}

Table 4: Kinematic viscosity (cst) of base fluids at different temperatures.

\begin{tabular}{lcccc}
\hline Temp $\left({ }^{\circ} \mathrm{C}\right)$ & Canola oil & EICO & Diesel & SHBF \\
\hline 25 & 66.5 & 3.5 & 3.2 & 2.9 \\
50 & 25.4 & 2.7 & 2.4 & 2.1 \\
75 & 13.2 & 2.1 & 1.7 & 1.3 \\
100 & 7.8 & 1.4 & 1.1 & 0.8 \\
\hline
\end{tabular}

TABle 5: Dynamic viscosity (cp) of base fluids at different temperatures.

\begin{tabular}{lcccc}
\hline Temp $\left({ }^{\circ} \mathrm{C}\right)$ & Canola oil & EICO & Diesel & SHBF \\
\hline 25 & 60.52 & 3.01 & 2.72 & 2.43 \\
50 & 22.76 & 2.27 & 2.00 & 1.72 \\
75 & 11.55 & 1.72 & 1.38 & 1.04 \\
100 & 6.72 & 1.13 & 0.86 & 0.62 \\
\hline
\end{tabular}

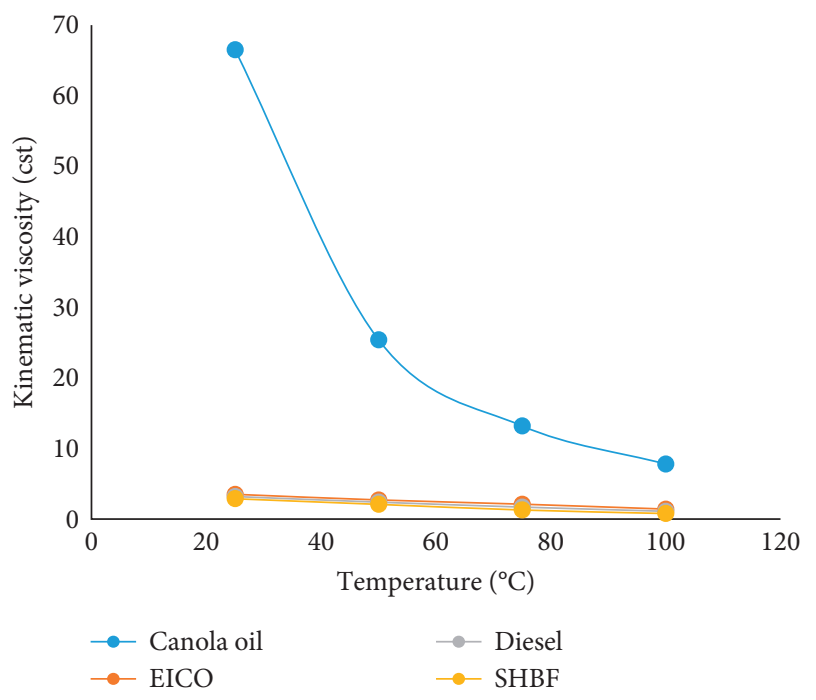

FIGURE 3: Kinematic viscosity variation with temperature.

and the travelling time reduces with temperature. This is partly connected with the high density of the fluid and presence of long chain fatty acid. The EICO took less time to travel down the viscometer just like the diesel and SHBF which are the standards and hence lower kinematic and dynamic viscosities.

Similarly, from the results presented in Tables 4 and 5 and Figures 3 and 4 for kinematic and dynamic viscosities, respectively, it was observed that the canola OBF has the highest kinematic and dynamic viscosity, respectively, at all temperatures. A lower kinematic viscosity is important because it allows the oil-based mud to be formulated at lower

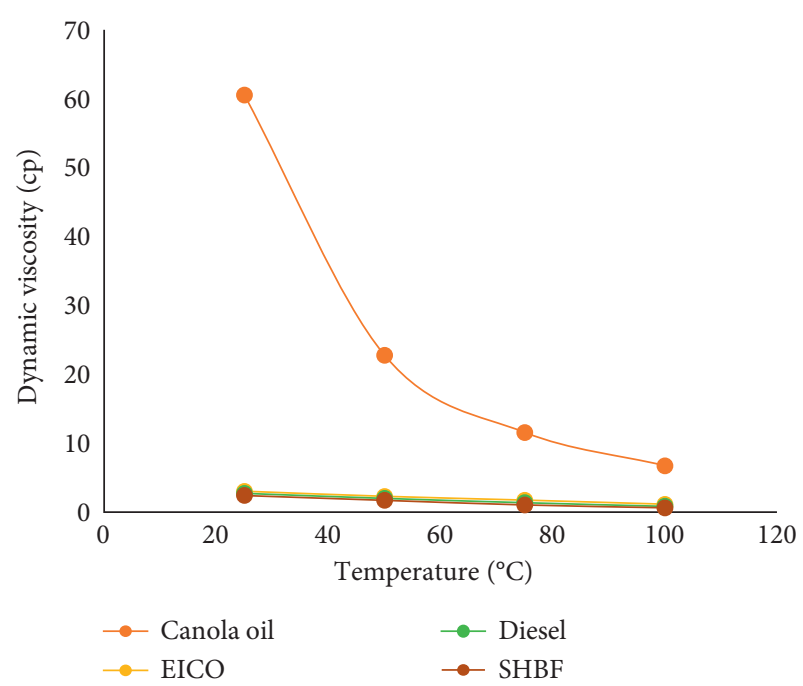

Figure 4: Dynamic viscosity variation with temperature.

TABle 6: Surface tension of fluid samples at $25^{\circ} \mathrm{C}$.

\begin{tabular}{lc}
\hline Base oil & Surface tension $(\mathrm{N} / \mathrm{m})$ \\
\hline Canola & 0.032 \\
EICO & 0.029 \\
Diesel oil & 0.028 \\
SHBF & 0.026 \\
\hline
\end{tabular}

TABLE 7: Cloud and pour points of base fluid samples.

\begin{tabular}{lcc}
\hline Base oil sample & Cloud point $\left({ }^{\circ} \mathrm{C}\right)$ & Pour point $\left({ }^{\circ} \mathrm{C}\right)$ \\
\hline Canola oil & 8 & 2 \\
EICO & 1 & -4 \\
Diesel & 2 & -1 \\
SHBF & 0 & -3 \\
\hline
\end{tabular}

TABLE 8: Flash point and fire point of base fluid samples.

\begin{tabular}{lcc}
\hline Base oil sample & Flash point $\left({ }^{\circ} \mathrm{C}\right)$ & Fire point $\left({ }^{\circ} \mathrm{C}\right)$ \\
\hline Canola oil & 284 & 315 \\
EICO & 165 & 185 \\
Diesel & 69 & 81 \\
SHBF & 76 & 87 \\
\hline
\end{tabular}

oil/water ratios and gives better rheology (lower plastic viscosity) at low mud temperature because too high viscosity increases pump pressure and limits flow properties and thus reduces penetration rates.

Also, the viscosity reduces with the increase in temperature as shown in Figures 3 and 4 because at higher temperature, there is induced movement. Lang et al. [25] and Noureddini et al. [26] also reported that the viscosity of canola and other vegetable oils decreases with an increase in temperature.

3.1.3. Surface Tension of Base Fluids. Drilling fluid surface tension measurement is very important in fluid characterization because high surface tensions decrease the ability of 


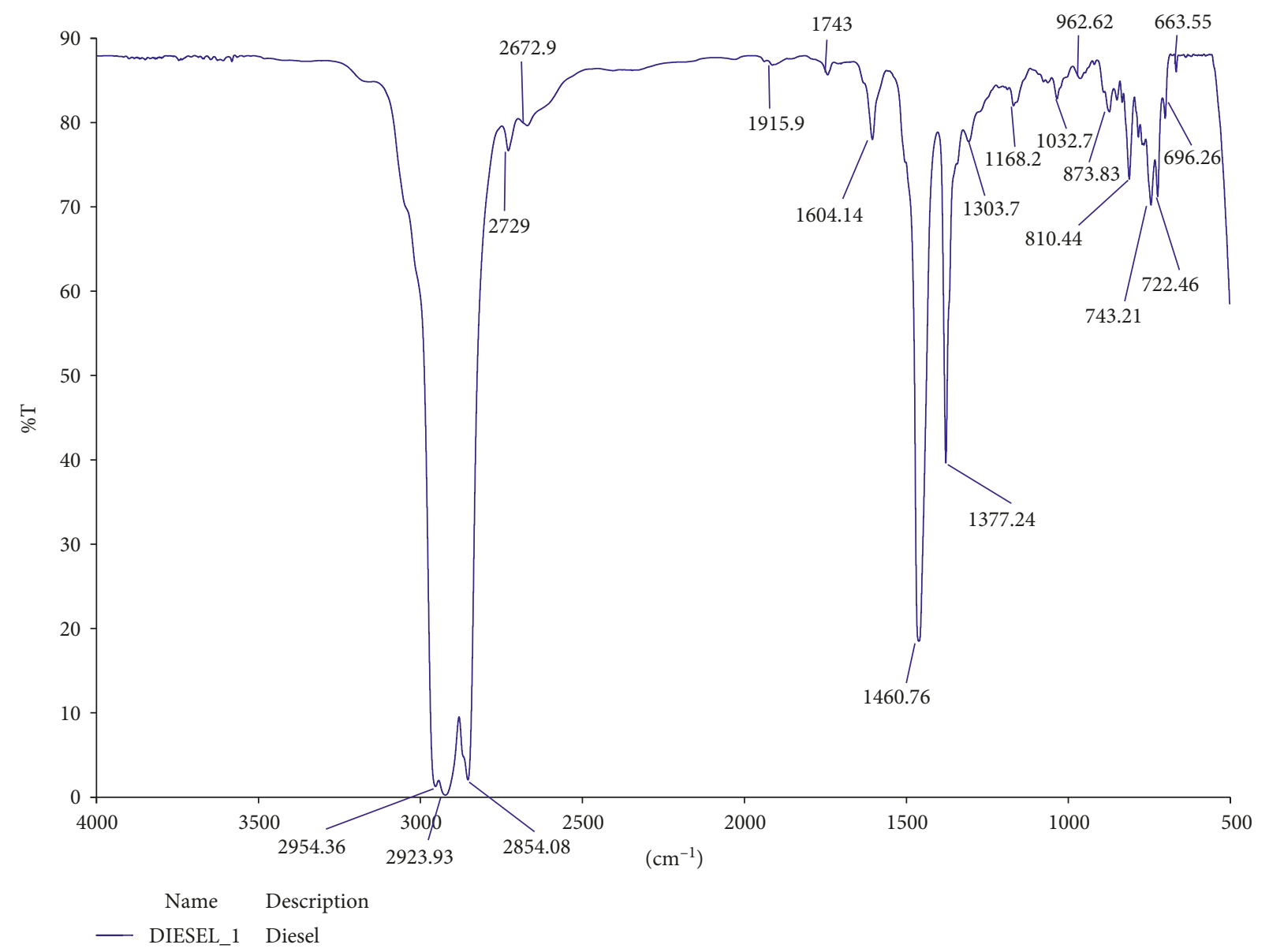

FIgURE 5: Diesel FTIR spectra.

the drilling fluid to pass through a shale shaker screen, particularly fine screens with their small openings [27].

Similarly, the reduced surface tension of EICO base fluid as shown in Table 6 would reduce the amount of surfactant (primary and secondary emulsifiers) required to lower the interfacial tension between oil and water during mud formulation. Bearing in mind that when the oil and water are mixed together mechanically, they separate immediately and the agitation ceases. Hence, lower base oil surface tension will reduce the amount of surfactants required to enable one liquid to form a stable dispersion of fine droplets in the other. Surface tension depends on the nature of the liquid, the surrounding environment, and temperature. The stronger the attractive intermolecular forces between liquids, the larger the surface tension. Surface tension decreases when temperature increases because cohesive forces decrease with an increase in molecular thermal activity.

3.1.4. Cloud Points and Pour Points of Base Fluids. The pour point is the lowest temperature at which a liquid will begin to flow while the cloud point is the temperature at which wax crystals begin to form in a liquid as it is cooled.

From Table 7, the canola oil OBF has higher pour points of $2^{\circ} \mathrm{C}$ which can make the OBMs to suffer from poor screening and excessive pressure, surges in deep water wells, or other operations that are subjected to low temperatures. But upon enzymatic transesterification, the pour point was significantly reduced to $-4^{\circ} \mathrm{C}$ which invariably means that little stresses are needed to be overcome before the base mud begins to flow.

Similarly, knowing the cloud point is important for determining storage stability. Storing formulations at temperatures significantly higher than the cloud point may result in phase separation and instability. Hence, the EICO SBF has low cloud points and hence can be stored under lower temperature conditions.

3.1.5. Flash Points and Fire Point of Base Fluid Samples. The flash point is the lowest temperature at which a liquid can form an ignitable mixture in air near the surface of the liquid. The lower the flash point, the easier it is to ignite the material. The fire point of a fuel is the lowest temperature at which the vapor of that fuel will continue to burn for at least 5 seconds after ignition by an open flame. At the flash point, a lower temperature, a substance will ignite briefly, but vapor might not be produced at a rate to sustain the fire. From Table 8, the EICO SBF has higher flash points of $165^{\circ} \mathrm{C}$ and fire point of $185^{\circ} \mathrm{C}$ which is good for forming SBMs because it really shows that the fluids can be worked with at higher temperature. According to Johanscvik and Grieve [28], the flash point of oil-based mud must be greater than $100^{\circ} \mathrm{C}$ as 


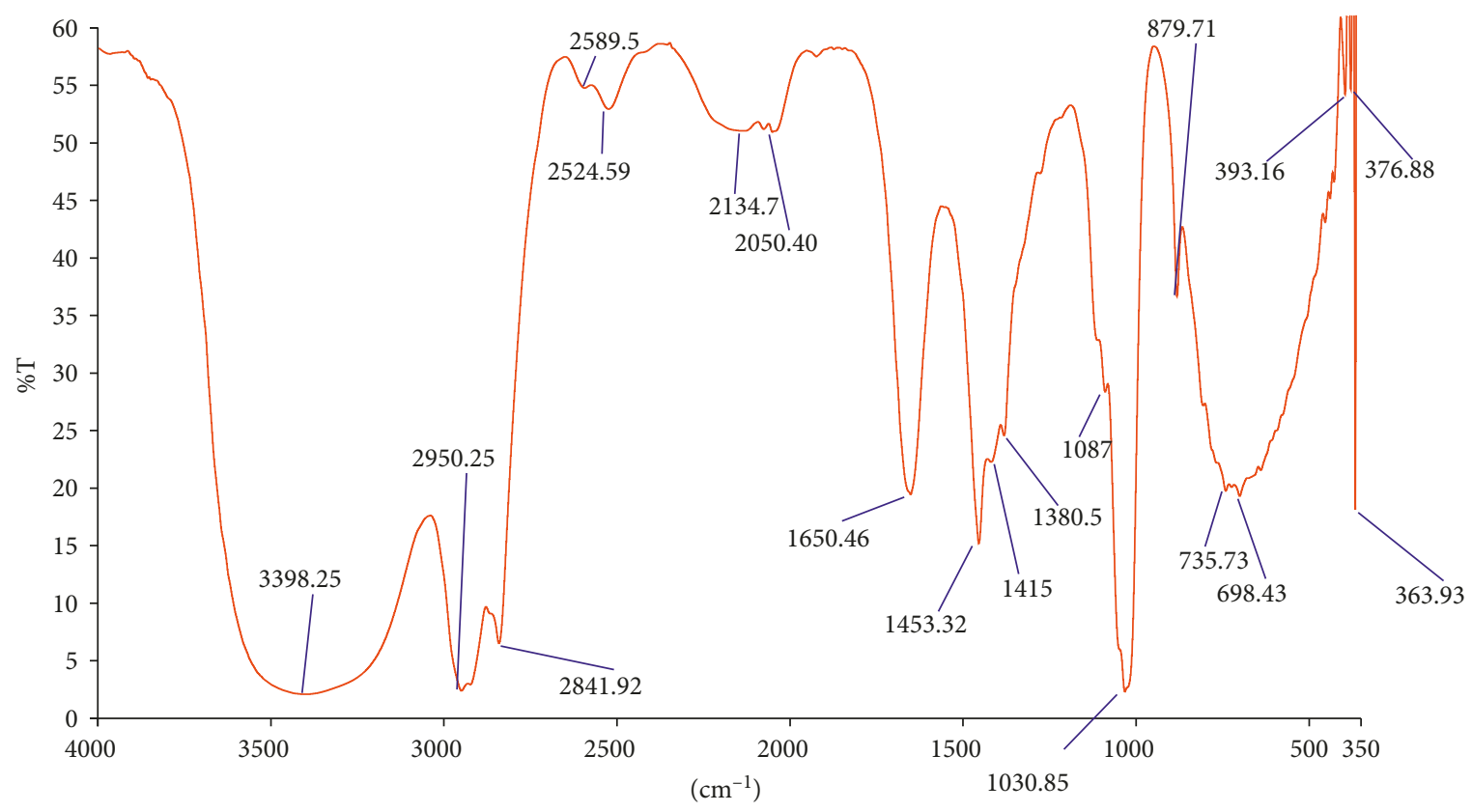

Name

Description

— SHBF_001_1 Sample SHBF by administrator date, Friday, March 23, 2018

FIgURE 6: SHBF FTIR spectra.

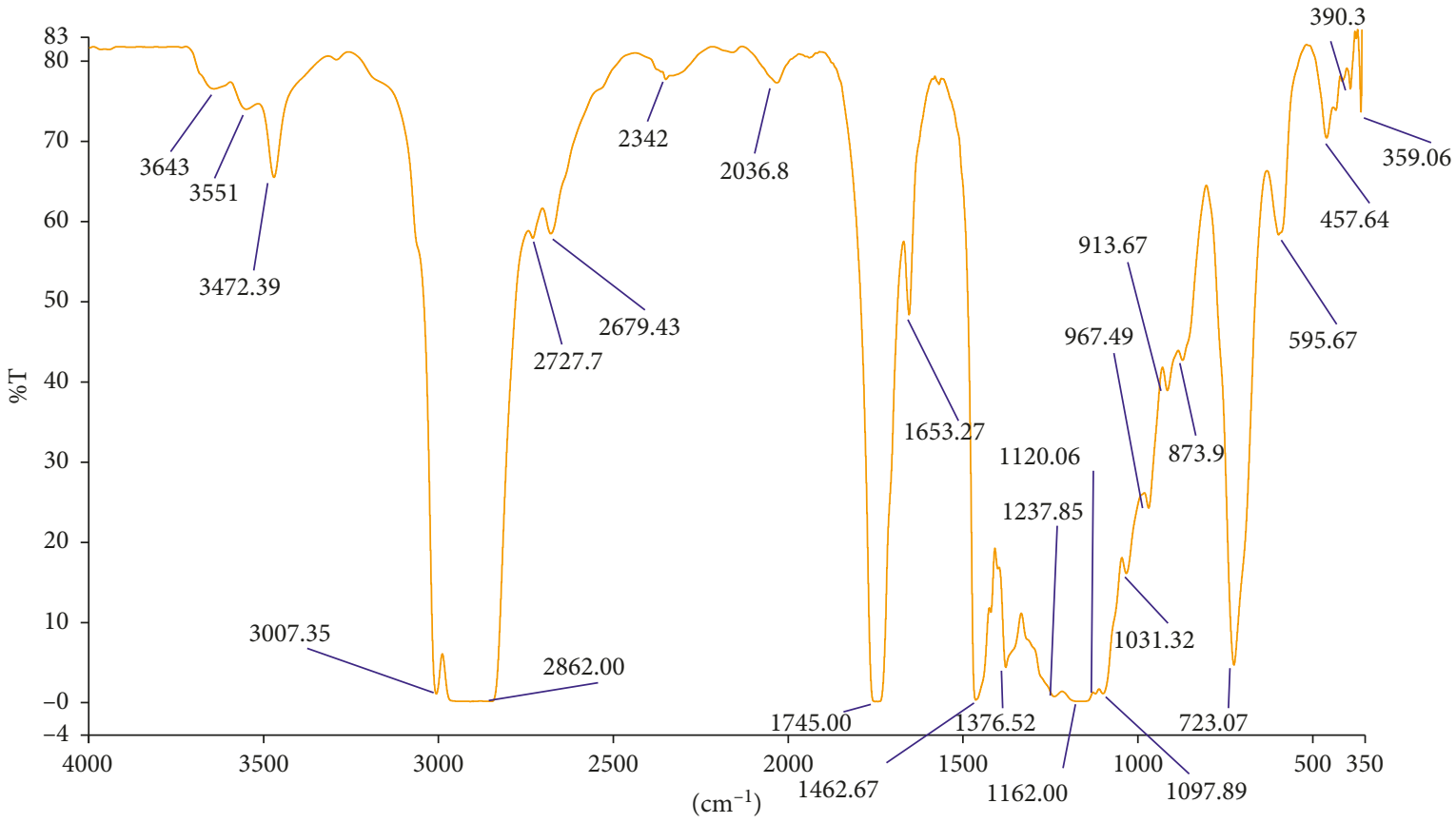

Name

Description

- CANOLA OIL_001_1_Sample canola oil by administrator date, Friday, March 23, 2018

FIgURe 7: Canola oil FTIR spectra.

higher flash point will minimize fire hazard because less hydrocarbon vapor is expected to generate above the mud.

3.1.6. Degree of Aromaticity. The relative degree of aromatic hydrocarbon present in a compound can be known through Fourier transform infrared spectroscopy (FTIR) spectra analysis. From FTIR spectra analysis, a well-defined absorption of one but typically two sets of bands in the region $1615 \mathrm{~cm}^{-1}-1495 \mathrm{~cm}^{-1}$ for aromatic ring stretch and $3130 \mathrm{~cm}^{-1}-3070 \mathrm{~cm}^{-1}$ for aromatic C-H stretch is consistent with aromatic compounds [29]. A careful look at diesel FTIR spectra (Figure 5) and SHBF spectra (Figure 6) showed that 


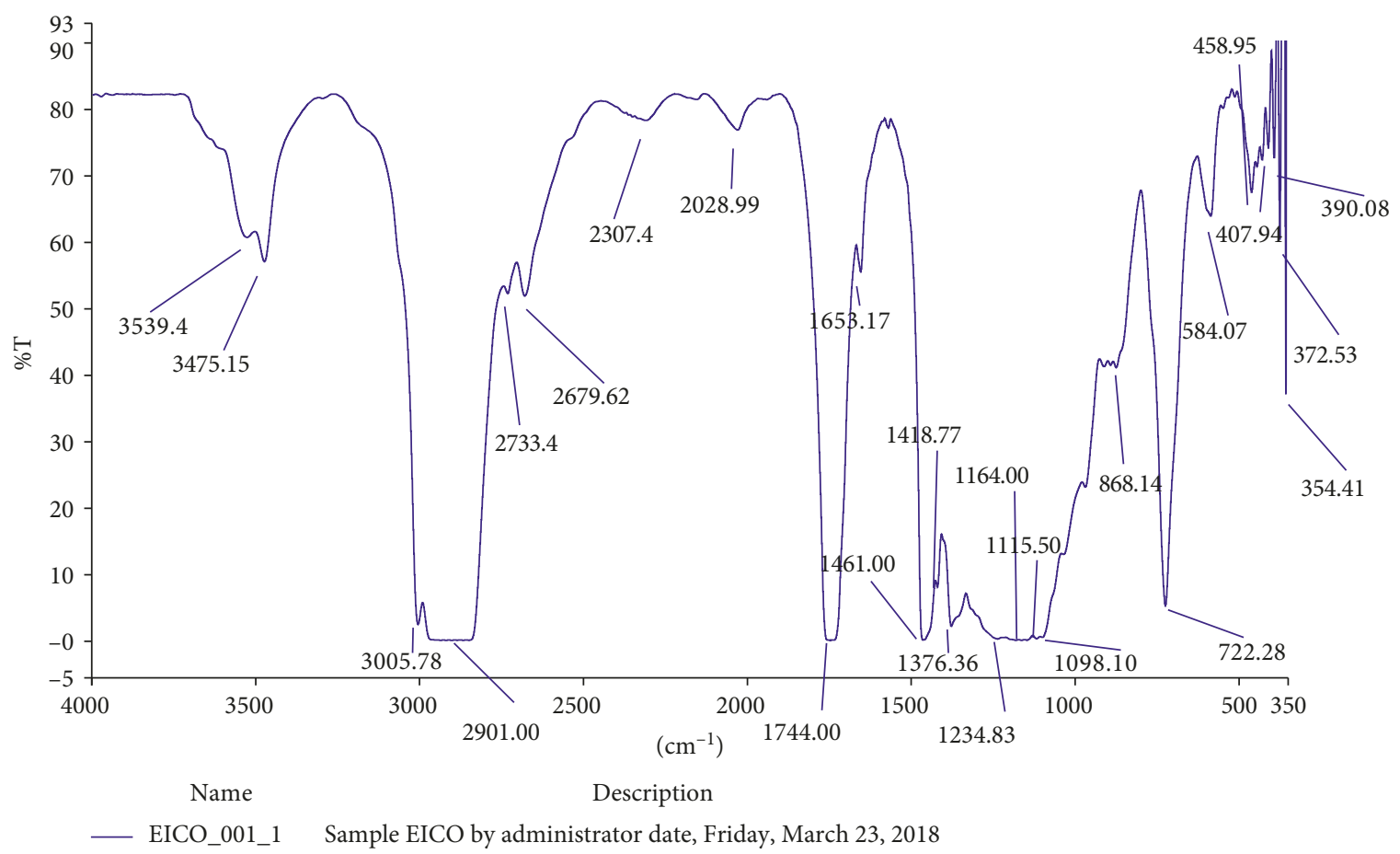

FIgURE 8: EICO FTIR spectra.

an aromatic ring stretch of $1604 \mathrm{~cm}^{-1}-1460 \mathrm{~cm}^{-1}$ and $1650 \mathrm{~cm}^{-1}-1453 \mathrm{~cm}^{-1}$ was found in diesel and SHBF FTIR spectrum, respectively. This aromatic ring stretch is absent in canola oil and the enzymatically interesterified canola oil (EICO) (Figures 7 and 8), respectively. However, field experience as well as laboratory tests has indicated that oils with a high aromatic content are more detrimental to rubber parts in a mud circulating system than those with low aromatic content.

Hence, oils with zero aromatic content are the most desirable for use in drilling fluids in order to minimize damage to rubber equipment on the rig and to reduce death of marine organism when the cuttings are discharged.

\section{Conclusions}

The following conclusions were drawn:

(i) The EICO gave $94.74 \%$ reduction in kinematic viscosity to conform to the standard kinematic viscosity requirement of base fluids to be used. For SBMs, a kinematic viscosity of 2.0 to $3.6 \mathrm{cp}$ is recommended according to API standard.

(ii) The cloud point and pour point were considerably reduced in the enzymatically synthesized canola oil, so that an account of possible cold environment operation can be easily accommodated without the SMBs losing their excellent rheological and filtration properties. Because higher pour points can make a SBM to suffer from poor screening and excessive pressure surges in deep water wells or other operations that are subjected to low operation.

(iii) Though the flash point and fire point were decreased after interesterification to a desirable level meaning that the fluids can still be worked with at higher temperatures without possible fair of ignition. Also, its transportation and storage ability will pose no threat.

(iv) A reduction of $5.50 \%$ in specific gravity was achieved with the enzymatic interesterification which consequentially helps to formulate SBMs that are of moderate density because loss of circulation may result from excessive pressure due to mud that is too dense or heavy and thus reduces rate of penetration and increase drilling cost.

(v) The produced fluid has no aromatic compound as evaluated by its FTIR Spectra analysis and thus no environmental pollution can arise from its cuttings discharge and no deterioration of the rubber part of drilling equipment can occur during drilling.

\section{Abbreviations}

EICO: Enzymatically interesterified canola oil

FTIR: Fourier transform infrared spectroscopy

OBF: Oil-based fluid

OBM: Oil-based mud

SBF: Synthetic-based fluid

SBM: Synthetic-based mud

SHBF: Synthetic hydrocarbon-based fluid

WBF: Water-based fluid

WBM: Water-based mud.

\section{Data Availability}

The data used in this study were obtained from rigorous experimental research in the laboratory and not from any 
journal either in print or online. The authors declare that the data will be available for public use.

\section{Conflicts of Interest}

The authors declare that there are no conflicts of interest regarding the publication of this paper.

\section{Acknowledgments}

The authors are very grateful to the Chancellor of Covenant University and the University Management team for their support for Research and Development and the IR unit of University of Ibadan without which this research work would not have seen the light of the day.

\section{References}

[1] PetroWiki, Drilling Fluids Types, 2017, http://petrowiki.org/ Drilling_fluid_types\#cite_ref-r1_1-0.

[2] A. Yassin, A. Kamis, and M. Abdullah, Palm Oil Diesel as Base Fluid in Formulating Oil based Drilling Fluid, Society of Petroleum Engineers, Dallas, TX, USA, 1991.

[3] O. Grahl-Nielsen, S. Sporst, C. E. Sjgren, and F. Oreld, The Five-Year Fate of Sea-Floor Petroleum Hydrocarbons from Discharged Drill Cuttings, Elsevier Applied Science, London, UK, 1989.

[4] F. V. Jones, C. Hood, and G. Moiseychenko, "International methods of evaluating the discharge of drilling fluids in marine environments," in Proceedings of the SPE International Conference on Health, Safety and Environment in Oil and Gas Exploration and Production, p. 18, Caracas, Venezuela, 1998.

[5] National Research Council, Drilling Discharges in the Marine Environment, National Academy Press, Washington, DC, USA, 1983.

[6] J. M. Neff, Biological Effects of Drilling Fluids, Drill Cuttings and Produced Waters. Long-term Effects of Offshore Oil and Gas Development, Elsevier Applied Science Publishers, London, UK, 1987.

[7] J. B. Hinwood, A. E. Poots, L. R. Dennis et al., "Drilling activities; environmental implications of offshore oil and gas development in Australia," in Proceedings of the Australian Petroleum Production and Exploration Association, pp. 123207, Canberra, Australia, 1994

[8] Norway, "Synthetic drilling fluids; proposal for a definition of synthetic drilling fluids and experiences on the Norwegian Continental Shelf," in Proceedings of the Oslo and Paris Conventions for the Prevention of Marine Pollution Working Group on Sea-Based Activities (SEBA), Biarritz, France, 1997.

[9] J. E. Friedheim and H. L. Conn, "Second generation synthetic fluids in the North Sea: are they better?," in Proceedings of the IADC/SPE Drilling Conference, pp. 215-228, New Orleans, LA, USA, March 1996.

[10] J. A. Veil and J. M. Daly, "Innovative regulatory approach for synthetic based drilling fluids," in Proceedings of the SPE/EPA Exploration and Production Environment Conference, Austin, TX, USA, February 1999.

[11] J. A. Veil, C. J. Burke, and D. O. Moses, "Synthetic based muds can improve drilling efficiency without pollution," Oil and Gas Journal, vol. 94, no. 10, pp. 49-54, 1996.

[12] M. Norman, "Esters-the only synthetic option for the next millennium?," in Proceedings of the 5th International [IBC]
Conference of Minimizing the Environmental Effects of Drilling Operations, Aberdeen, UK, p. 13, June 1997.

[13] J. Steber, C. P. Herold, and J. M. Limia, Solving Fluid Biodegradation in Seabed Drill Cuttings Pile, Offshore, 1994.

[14] J. E. Candler, S. P. Rabke, and J. J. Leuterma, "Predicting the potential impact of synthetic-based muds with the use of biodegradation studies," in Proceedings of the 1999 SPE/EPA Exploration and Production Environmental Conference, Austin, TX, USA, March 1999.

[15] E. A. Vik, B. S. Nesgard, J. D. Berg et al., "Factors affecting methods for biodegradation testing of drilling fluids for marine discharge," in Proceedings of the SPE International Conference on Health, Safety and Environment, New Orleans, LA, USA, pp. 697-711, June 1996.

[16] T. K. Mag, "Bleaching theory and practice," in Proceedings of the Edible Fats and Oils Processing World Conference, pp. 107-116, Champaign, IL, USA, 1990.

[17] R. G. Ackman, Canola Fatty Acids-An Ideal Mixture for Health, Nutrition, and Food Use. Canola and Rapeseed, Springer, Boston, MA, USA, 1990.

[18] F. D. Gunstone, Vegetable Oils. Industrial Oil and Fat Products, Vol. 1, John Wiley \& Sons, Hoboken, NJ, USA, 6th edition, 2006.

[19] M. Kellens, Oil Processing Challenges in the 21th Century: Enzymes Key to Quality and Profitability, Desmet Ballestra Group, Zaventum, Belgium, 2000.

[20] Stanhope-seta, Seta Cloud and Pour Point Cryostat, 2017, http://www.stanhope-seta.co.uk/view_pdf.asp?strPdf=935317_Cloud_Pour_Point.pdf\&strPage $=$ dl.

[21] Stanhope-seta, Seta Flash Point Tester, 2017, http://www. stanhope-seta.co.uk/flashpoint- testing.asp.

[22] C. Huh and S. G. Mason, "A rigorous theory of ring tensiometry," Colloid and Polymer Science, vol. 253, no. 7, pp. 566-580, 1975.

[23] W. D. Harkins and H. F. Jordan, "A method for the determination of surface and interfacial tension from the maximum pull on a ring," Journal of the American Chemical Society, vol. 52, no. 5, pp. 1751-1772, 1930.

[24] N. J. Hyne, Dictionary of Petroleum Exploration, Drilling and Production, Pen Well Publishing Company, Tulsa, OK, USA, 1991.

[25] W. Lang, F. W. Sosulski, and S. Sokhansanj, "Modelling the temperature dependence of kinematic viscosity for refined Canola oil," Journal of American Oil Chemist Society, vol. 69, no. 10, pp. 1054-1055, 1992.

[26] H. Noureddini, B. C. Teoh, and L. D. Clements, "Densities of vegetable oils and fatty acids," Journal of American Oil Chemist Society, vol. 69, no. 10, pp. 1184-1188, 1992.

[27] ASME Shale Shaker Committee, Drilling Fluids Processing Handbook, Gulf Professional Publishing, Houston, TX, USA, 2004.

[28] C. Johanscvik and W. R. Grieve, "Oil-based mud reduces bore-hole problems," Oil and Gas Journal, vol. 4, p. 47, 1987.

[29] J. Coates, "Interpretation of infrared spectra, a practical approach," in Encyclopedia of Analytical Chemistry, R. A. Meyers, Ed., John Wiley \& Sons, Chichester, UK, 2000. 


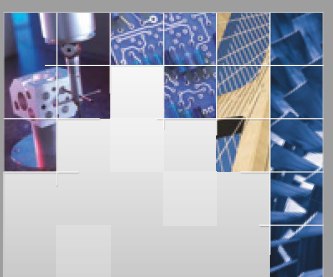

\section{Enfincering}
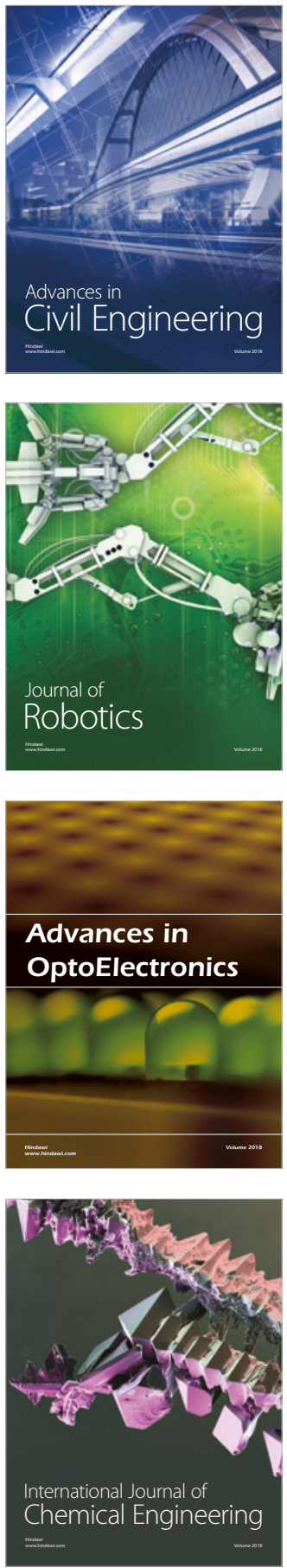

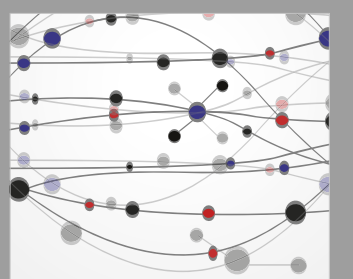

\section{Rotating \\ Machinery}

The Scientific World Journal

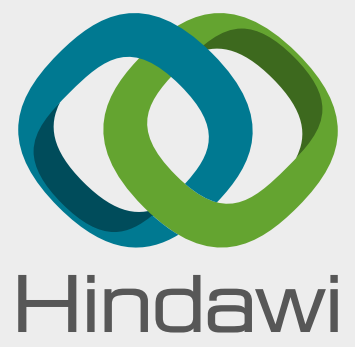

Submit your manuscripts at

www.hindawi.com
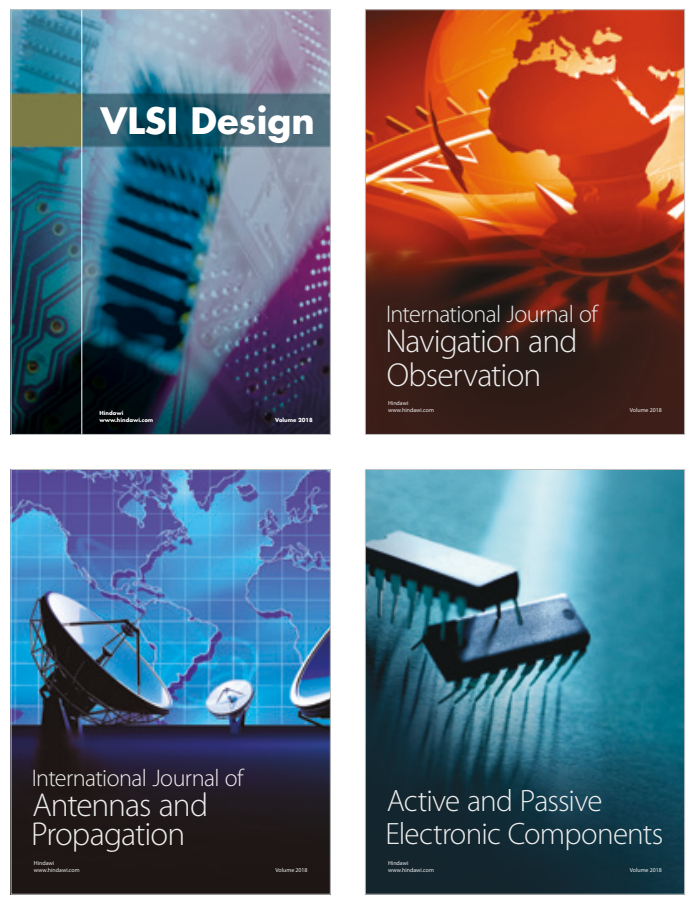
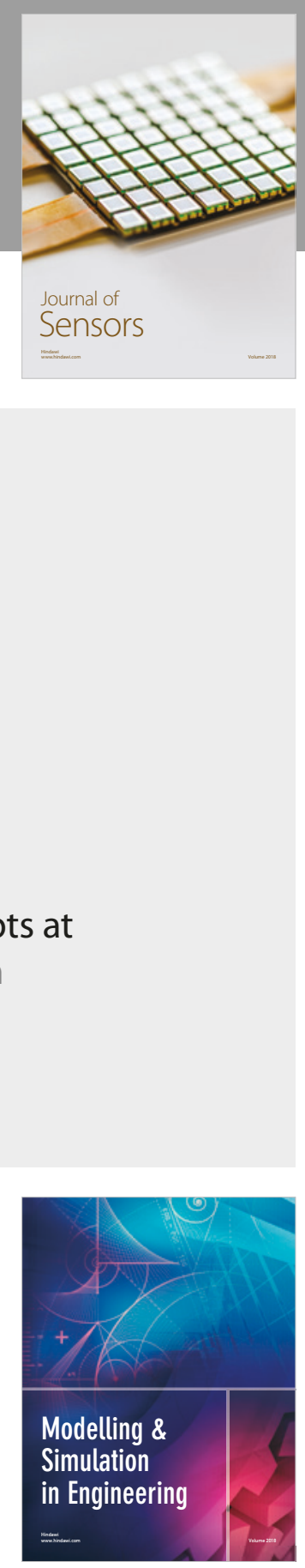

\section{Advances \\ Multimedia}
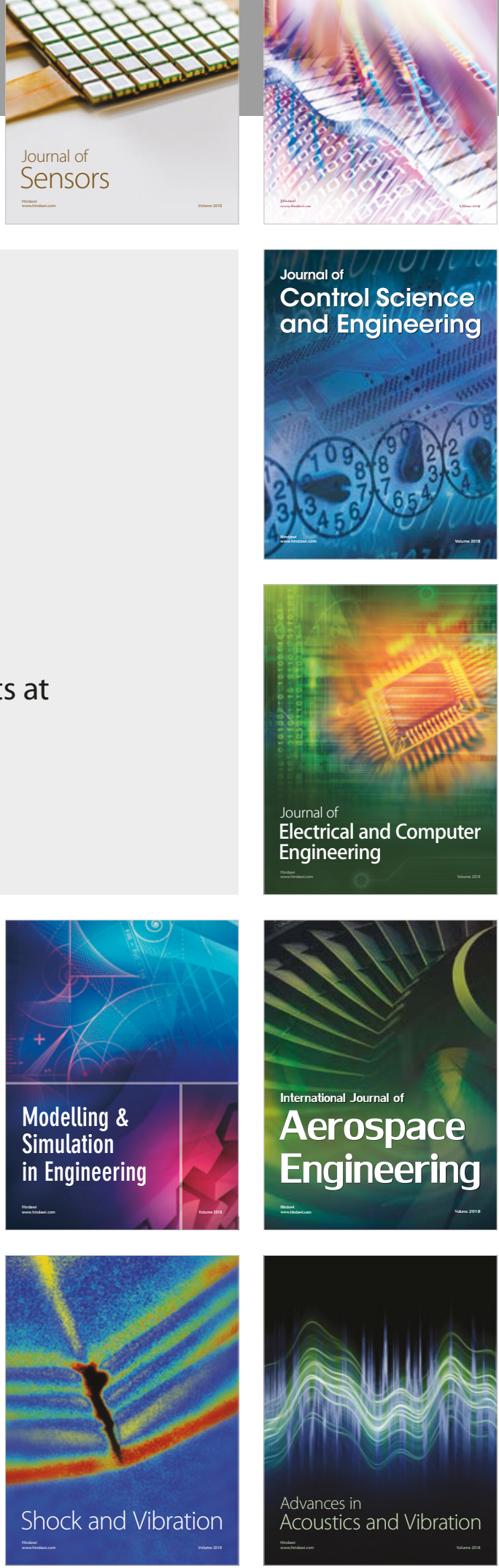